\title{
LEVANTAMIENTO DE ACTAS POR REASIGNACIÓN PARA LA CONCORDANCIA SEXOGENÉRICA, UNA FORMA DE EVITAR LA DISCRIMINACIÓN
}

El primer antecedente que tenemos respecto a la reasignación para la concordancia sexogenérica es una decisión salomónica del pleno de la Suprema Corte de Justicia de la Nación (SCJN) en el "Amparo directo civil 6/ 2008" que declaró constitucional el artículo 138 bis del Código Civil del Distrito Federal, el cual establece que el cambio de sexo debe quedar registrado en el acta de nacimiento original; pero contrario a ello, la mayoría se pronunció en favor de conceder amparo a la quejosa, argumentando que el artículo referido es "discriminatorio" y viola sus garantías individuales. Arribaron a esta decisión con siete votos a favor y cuatro en contra, concediendo el amparo a la persona transexual que interpuso un juicio para borrar de su acta de nacimiento la anotación marginal que explicaba el nombre y el sexo que tenía antes de modificarlos legalmente, la protección de la justicia federal se concedió a efecto de que el Registro Público del Distrito Federal emita una nueva acta sin anotaciones marginales y que sólo el interesado tenga acceso al acta original — que tenga la corrección del género y nombre de la demandante - o mediante mandato judicial o ministerial.

En el caso que nos ocupa, particularmente se trató de un juicio de rectificación de acta en el renglón relativo al nombre y sexo, para cambiar de hombre a mujer, esto en una persona hermafrodita que después de haber sido tratada hormonalmente tiene aspecto físico, sicológico y social de una mujer. Posteriormente se sometió a una cirugía de reasignación sexual para superar "la discordancia entre sus características biológicas 
de nacimiento y su sentido de pertenecer al género femenino", señala el expediente de la causa.

El juez de origen determinó que el director del Registro Civil del Distrito Federal rectificara el acta de nacimiento y asentara mediante una anotación marginal, un nuevo nombre para el registrado y en el caso del sexo será femenino. Sin embargo, consideró improcedente la petición relativa a que no se publicara ni se expidiera constancia alguna que revelara la condición de su persona y se levantara una nueva acta. Además, el juez agregó que los alcances de su resolución son únicamente los de ajustar el nombre y el sexo de la parte actora a la realidad jurídica y social, sin implicar un cambio en sus derechos civiles. Ante esta situación, la parte quejosa, que había solicitado que se le aplicaran las normas de expedición de actas que se emplean a los hijos adoptados y a los que son reconocidos con posterioridad a su inscripción en el Registro, interpuso amparo contra la sentencia.

El quejoso, quien ya se maneja como mujer en su vida cotidiana, interpuso una serie de recursos para exigir la expedición de una nueva acta, posibilidad que le fue negada en última instancia en la primera sala de lo familiar del Tribunal Superior de Justicia del Distrito Federal, concluyó que la naturaleza jurídica del asunto reviste un gran interés, importancia y trascendencia, entre otras razones porque su resolución requiere de un desarrollo analítico detallado en torno al principio o derecho a la igualdad y a la no discriminación, así como un análisis jurídico basado en la vulneración del derecho a la privacidad, la dignidad personal y el acceso a la salud, resolviendo que la nota marginal en su acta no violaba los principios de igualdad, discriminación, privacidad, salud y dignidad humana. Aunado a que en el momento y procedimiento que él lo solicito el Código Civil no preveía la emisión de una nueva acta solo la anotación marginal siendo correcto que no se podía resolver mas allá de lo que la ley les permitía.

La Primera Sala de la Suprema Corte de Justicia de la Nación (SCJN) determinó ejercer su facultad de atracción para resolver un amparo promovido por una persona que, a raíz de su cambio de sexo, solicitó que no se publicara ni se expidiera constancia alguna que revelara su cambio de identidad, cuestión que le negó un juez.

Los ministros señalaron que el asunto reviste importancia y trascendencia porque incide en la delimitación de las condiciones que estructu- 
ran la convivencia en México y que hacen para ciertas personas más fácil o más difícil la inserción en la sociedad mayoritaria.

Por tal razón, deberán pronunciarse no sólo acerca de cuestiones de atención sanitaria, farmacológica y quirúrgica, y de la constitucionalidad del artículo 138 del Código Civil para el Distrito Federal que obliga a hacer una anotación marginal del acta rectificada, sino también de aspectos que tienen que ver con la regulación jurídica en materia de datos que afectan a la identidad.

Así lo determinaron los ministros al ejercer su facultad de atracción, para conocer y resolver un amparo promovido por una persona que a raíz de su cambio de sexo, solicitó, además de la rectificación de su acta de nacimiento, que no se publicara ni se expidiera constancia alguna que revelara su cambio de identidad.

El artículo 138 bis prevé textualmente:

La aclaración de las actas del estado civil, procede cuando en el levantamiento del acta correspondiente, existan errores mecanográficos, ortográficos, o de otra índole, que no afecten los datos esenciales de aquéllas, y deberán tramitarse ante la Dirección General del Registro Civil.

El Reglamento del Registro Civil, establecerá los supuestos, requisitos y procedimientos para realizar la aclaración de las actas del Estado Civil.

La inconstitucionalita por sí sola no se da, ya que ésta radica en el acto de aplicación, porque en el artículo señalado se prevé la modificación del acta y las notas marginales, pero no la emisión del nuevo documento, mismo que no se procura en el momento en que se hace la petición y que en el Código Civil solamente prevé la rectificación de acta que es un procedimiento distinto al procedimiento especial para la reasignación de sexo en donde se estaría tocando un tema totalmente diferente el cual aún no estaba especificado en el Código Civil al momento de su petición.

Cuando se emitió este criterio se acababan de aprobar las modificaciones al Código Civil capitalino, que en su artículo 135 bis señala que el acta con las anotaciones es de acceso reservado y que la persona que cambie de sexo obtendrá una nueva, era suficiente dicha prevención para proteger los derechos individuales. En cambio la minoría de los ministros (José Ramón Cossío, Olga Sánchez Cordero, Sergio Valls —autor del proyecto-, Juan N. Silva Meza y Genaro Góngora Pimentel) determinó que la anotación en el acta primigenia es inconstitucional. Al respecto, 
Góngora argumentó que "aunque la anotación marginal en sí misma puede no ser discriminatoria, sus consecuencias sí, lo cual la hace violatoria del principio de igualdad". Añadió que la discriminación por preferencia sexual "no es cuestión hipotética, que puede ocurrir o no", sino "realidad cotidiana". Agregó que la primera encuesta nacional sobre discriminación en México, publicada en mayo de 2005, reveló que 48.5 por ciento de mexicanos no permitirían que una persona homosexual viviera en su casa. Comentó que, según estimaciones, de 1995 a 2005 ocurrieron 337 homicidios por razones homofóbicas.

Al igual que sus compañeros, indicó que no se trata de que desaparezca la persona que cambia de sexo al expedirse un acta nueva, porque su nombre y género estarán en el acta primigenia, que obrará en el Registro Civil, por lo que seguirá siendo responsable de las obligaciones contraídas.

Con esta decisión, la SCJN retomó como "principio general de derecho" a las reformas a los códigos Financiero, Civil y de Procedimientos Civiles que fueron aprobados por la Asamblea Legislativa del Distrito Federal (ALDF) en 2009 y que recientemente entraron en vigor en la capital de la República, toda vez que atienden al principio de no discriminación consagrado en el párrafo tercero del artículo 10. constitucional.

Al paralelo, la Corte consideró, por mayoría, que no es inconstitucional el artículo 138 del Código Civil del Distrito Federal, el cual establece que después de lograr la rectificación del acta de nacimiento, se colocará al margen de dicho documento una referencia sobre la identidad anterior de quien decidió cambiar jurídicamente.

Tras el amparo, el acta de nacimiento primigenia con anotación marginal será reservada, no se expedirá constancia alguna, salvo mandamiento judicial, y el juez del Registro Civil dará parte a la Oficina Central, a las secretarías de Gobernación y Relaciones Exteriores, al Instituto Federal Electoral, así como a las procuradurías del Distrito Federal y de la República para efectos legales procedentes. Por lo que dichas reformas lo que van a simplificar los trámites, buscando con ello que no sea necesario que las personas transexuales tengan que amparase en cada uno de sus tramites y que solo se refieran a un acta de nacimiento acorde a su identidad de género y sin anotaciones al margen que expliquen su pasado, 
esto es así toda vez que con fecha 10 de octubre de $2008^{1}$ se publicaron en la Gaceta Oficial del Distrito Federal las reformas y adiciones a los artículos 2o., 35, 98 y 135 bis del Código Civil del Distrito Federal y la adición al capítulo IV bis al título séptimo del Código de Procedimientos Civiles para el Distrito Federal.

Estas reformas tienen su justificación inicialmente en que el derecho es una ciencia en constante evolución y que debe adecuarse a la realidad social, que las sociedades se transforman a una velocidad mayor que las normas jurídicas, encontrando el hecho de que las personas cuya identidad de género puede no ser acorde con su sexo, a tener la oportunidad de auxiliarse de la ciencia con la finalidad de obtener una concordancia entre su identidad de género y su imagen corporal y su sexo; sin embargo esto no es suficiente para estas personas, las cuales necesitan imperativamente de una regulación jurídica que les permita homologar su identidad jurídica con su realidad social.

Para poder entender lo anterior es necesario vertir en este momento los conceptos básicos en relación al problema que esta iniciativa pretende resolver, que es dar certeza jurídica a las personas transgénericas, transexuales y travestistas, las cuales reclaman el reconocimiento y otorgamiento de sus derechos al libre desarrollo de su personalidad jurídica, siempre y cuando no se lesionen derechos de terceros.

Por sexo se entiende al conjunto de características biológicas que conforman a un ser humano y que por lo menos contiene ocho elementos: sexocromosómico, génico, de órganos sexuales externos e internos pélvicos, hormonal, gonadal, de caracteres sexuales secundarios, y cerebral.

La identidad de género constituye la condición humana de pertenecer al género masculino o femenino, es inmodificable y no siempre concuerda con el sexo.

La expresión de rol de género es el conjunto de manifestaciones relacionadas con la vestimenta, expresión corporal y/o verbal, y el comportamiento, con independencia de que se considere o no propio del género masculino o femenino.

La persona transexual encuentra que su identidad de género no coincide con su anatomía. Es decir, se produce una discordancia entre su sexo

1 Exposición de motivo de las reformas. Reasignación para la concordancia de sexo, 10 de octubre de 2008, Gaceta Oficial del Distrito Federal, http://www.scjn.gob.mx/MediosPub/Noticias/2008/Paginas/Noticia20080514.aspx 
(aspectos biológicos) y su identidad de género. Estas personas refieren vivir atrapadas en un cuerpo que no les corresponde.

Una persona transgenérica es la que vive permanentemente y de manera voluntaria en el rol que corresponde al otro género, distinto al que le fue asignado al momento de su nacimiento.

El travestismo es una expresión humana caracterizada por el uso de vestimenta, lenguaje, y expresión corporal que se no se consideran propios del género que le fue asignado al momento de su nacimiento.

La reasignación para la concordancia sexogenérica es el proceso de intervención profesional mediante el cual la persona obtiene concordancia entre los aspectos corporales y su identidad de género, y que puede incluir parcial o totalmente: entrenamiento de expresión de rol de género, administración de hormonas, intervención quirúrgica y psicoterapia de apoyo.

Esta situación produce desigualdad jurídica de estos grupos ante el resto de la sociedad, al tener la incapacidad de acreditar jurídicamente su identidad, ya que no cuentan con un acta de nacimiento que refleje su identidad de género lo que les impide vivir su realidad social y el ejercicio pleno de sus derechos.

\section{Contenido de la reforma}

En el ámbito sustantivo que contempla el Código Civil enmarca la capacidad jurídica de las personas (aptitud para ser titular de derechos y obligaciones) que es igual para cualquier hombre o mujer, sin embargo, en el caso de las personas transgénericas, transexuales y travestistas, no se reconoce, y por lo tanto es necesario reconocerles a partir de la aprobación de esta iniciativa su capacidad de goce y ejercicio, entendiendo a la primera como la capacidad de tener derechos y obligaciones, y la segunda como la capacidad de ejercer dichos derechos y contraer de forma personal obligaciones.

En este sentido, se modificó el artículo 2o. del Código Civil para el Distrito Federal la incorporación de la identidad de género y la manifestación de rol de género circunstancia que garantiza la no discriminación y la no restricción el ejercicio de sus derechos por identidad o manifestación de rol de género. 
En el artículo 35 se adicionó lo referente a las interlocutorias que ordenan la rectificación del acta por reasignación para la concordancia sexogenérica.

Una modificación de suma importancia es la realizada al artículo 98 del Código Civil, el cual se refiere a los requisitos para contraer matrimonio, y entre los cuales adicionamos la manifestación bajo protesta de decir verdad en la que se exprese si alguno de los contrayentes ha realizado el procedimiento para la reasignación para la concordancia sexogenérica, a fin de dar certeza a jurídica a ambos contrayentes en relación a la persona con quien van a contraer nupcias y evitar en dado momento la nulidad del matrimonio por error en la persona.

Pueden pedir el levantamiento de una nueva acta de nacimiento por reasignación de concordancia sexogenérica, previa la anotación correspondiente en su acta de nacimiento primigenia, las personas que requieran el reconocimiento de su identidad de género.

La reasignación para la concordancia sexogenérica es el proceso de intervención profesional mediante el cual la persona obtiene concordancia entre los aspectos corporales y su identidad de género, que puede incluir, parcial o totalmente: entrenamiento de expresión de rol de género, administración de hormonas, psicoterapia de apoyo o las intervenciones quirúrgicas que haya requerido en su proceso; y que tendrá como consecuencia, mediante resolución judicial, una identidad jurídica de hombre o mujer, según corresponda.

Se entenderá por expresión de rol de género, el conjunto de manifestaciones relacionadas con la vestimenta, la expresión corporal o verbal y el comportamiento.

Es importante destacar los derechos y obligaciones contraídas con anterioridad a la reasignación para la concordancia sexogenérica no se modifican ni extinguen con la nueva identidad jurídica de la persona.

El procedimiento está regulado en los artículo 498, 498 bis del Código de Procedimientos Civiles que iniciará con la demanda ante el juez de lo familiar en turno donde se solicite el levantamiento de una nueva acta de nacimiento por reasignación de concordancia sexogenérica, previa anotación correspondiente al acta de nacimiento primigenia.

Se deberá cumplir con los siguientes requisitos:

I. Ser de nacionalidad mexicana; 
II. Mayor de edad o actuar a través de quien ejerza sobre la persona la patria potestad o tutela;

III. Anexar a la demanda el dictamen que determine que es una persona que se encuentra sujeta al proceso de reasignación para la concordancia sexogenérica con un mínimo de cinco meses, expedido por dos profesionistas o peritos que cuenten con experiencia clínica en materia de procesos de reasignación para la concordancia sexogenérica, uno de ellos deberá ser el profesionista a cargo del tratamiento del solicitante.

Así como manifestar lo siguiente:

I. El nombre completo y sexo original de la persona promovente, con los datos registrales correspondientes;

II. El nombre sin apellidos y, en su caso, el sexo solicitado.

Una vez presentada y admitida la demanda por el Juez de lo Familiar se dará vista al Registro Civil del Distrito Federal y a la Procuraduría de Justicia del Distrito Federal, a través del Ministerio Público adscrito al juzgado; para que dentro del término de cinco días hábiles manifiesten lo que a su derecho convenga.

Además de señalar fecha y hora para la audiencia de pruebas y alegatos, que se llevará a cabo dentro de los quince días hábiles siguientes.

El promovente deberá comparecer a la audiencia con los peritos que hayan emitido los dictámenes en que se funde la demanda. En caso de ausencia de los peritos, se tendrá por desierta la probanza.

En dicha audiencia, el Juez podrá cuestionar a los peritos sobre el contenido de los dictámenes emitidos y podrá ordenar la práctica y el desahogo de los dictámenes periciales que considere necesarios, única y exclusivamente para determinar la procedencia de la acción; en cuyo caso se podrá suspender la audiencia hasta por diez días hábiles. También podrá interrogar a los testigos, si se hubieren ofrecido y presentado, para los mismos efectos que los peritos.

Cuando el Registro Civil haya manifestado oposición a la solicitud del promovente, deberá ofrecer las pruebas que considere necesarias para acreditar su dicho cuando se le dé vista con la demanda y comparecerá a la audiencia para su desahogo. 
Desahogadas todas las pruebas, el promovente y al Agente del Ministerio Público adscrito podrán formular sus alegatos, hecho esto el Juez citará para oír sentencia dentro del término de diez días hábiles.

Pueden apelar el promovente, así como el agente del Ministerio Público, recurso que se admitirá en ambos efectos.

Una vez que cause ejecutoria la sentencia favorable el Juez ordenará de oficio, dentro del término de cinco días hábiles posteriores la anotación correspondiente al acta de nacimiento primigenia y el levantamiento de una nueva acta de nacimiento por reasignación de concordancia sexogenérica.

El acta de nacimiento primigenia quedará reservada y no se publicará ni expedirá constancia alguna, salvo mandamiento judicial o petición ministerial.

El juez del Registro Civil remitirá oficio a la Oficina Central y al lugar donde se encuentra la base de datos; así como enviará dicha información, en calidad de reservada, a la Secretaría de Gobernación, Secretaría de Relaciones Exteriores, Instituto Federal Electoral, Procuraduría General de Justicia del Distrito Federal y Procuraduría General de la República, para los efectos legales procedentes.

Cuando la persona hubiese obtenido el levantamiento de una nueva acta de nacimiento con motivo de reasignación para la concordancia sexogenérica, y ésta no sea acorde con su identidad de género, procederá su restitución siguiendo el mismo procedimiento previsto en este capítulo.

De la anterior reforma no comparto dos supuestos que la concordancia sea parcial, ya que a mi parecer si el interesado lo que pretende es parecer físicamente de otro sexo al que naturalmente tiene, el proceso de reasignación debe de ser total, es decir, tener apariencia de hombre o de mujer.

Asimismo, la posibilidad que prevé la ley de hacer reversible esta reasignación considero que es un supuesto muy serio en el que se está involucrando la identidad de una persona y el tramitar un procedimiento de este estilo para cambiar su identidad de hombre a mujer por ejemplo y luego regresar a ser un hombre no puede ser una conducta caprichosa, sino el resultado como ya hemos analizado de una necesidad de la persona transgénica de adecuar su físico e identidad a su verdadera.

Como juez de lo familiar en el Distrito Federal, tuve la oportunidad de dictar el 6 de enero de 2009 la primera sentencia que autorizó el levanta- 
miento de un acta de reasignación para la concordancia sexogenérica, sin que la misma haya representado mayor dificultad, ya que el solicitante, un varón, que desde la edad de tres años sintió una plena identificación con el sexo femenino, y el cual se pretendía como mujer, siendo éste su mayor anhelo en la vida; además de que en su entorno familiar siempre se tuvo aceptación de este tema, ya que sus padres se referían hacia él como "nuestra niña"; sin embargo, su situación no concordaba con el sexo masculino, con el cual estaba consciente haber nacido; que su comportamiento femenino y su cara de niña siempre eran motivo de burlas, lo que le hacía tener sentimientos de angustia y tristeza hasta llegar a la depresión; que en la etapa escolar su comportamiento fue normal, pero cuando se acentuaron sus cambios físicos abandonó la escuela, ya que no deseaba mostrarse con su apariencia cada vez más masculina de su persona; al tener la firme convicción de vivir como mujer en el cuerpo de un hombre, inició la búsqueda de información hasta que descubrió la situación de la transexualidad, teniendo la certeza de que era su caso, y por tal motivo decidió frenar sus cambios físicos, con los cuales no estaba de acuerdo, hasta llegar a la automedicación con hormonas femeninas; la fuerte atracción por los niños le permitió vivir con el rol de género femenino las 24 horas del día, sintiéndose feliz y plena con dicha situación.

En febrero de 1998 acudió por primera vez a cita con su médico tratante, contando con la edad de 17 años, sometiéndose a pruebas, tests y tras un periodo de terapia le confirmó su diagnóstico de mujer transexual; que a la edad de 14 años tuvo novios de sexo masculino, con los que nunca tuvo problemas para mantener relaciones amorosas y sexuales, siendo dicha situación un factor determinante para decidir por completo su reasignación, a fin de tener relaciones plenas como mujer, por tal motivo a la edad de 26 años se sometió al proceso de cirugía de reasignación sexual (CRS), con su médico y bajo la estricta supervisión de su médico tratante, por lo que estaba preparada para asumir plenamente su rol de mujer transexual; que en lo social tiene una pareja varón que conoce perfectamente su situación y con quien comparte su vida sentimental; que por ello, es su deseo el cambiar de nombre y sexo en el acta de nacimiento, ya que en la vida cotidiana lo ha venido realizando, lo que constituiría no sólo el último paso de la reasignación para la concordancia sexogenérica, sino que representa el único obstáculo para formar y compartir el hogar que desea construir con su pareja varón heterosexual, con quien se encuentra unida sentimentalmente desde hace muchos años, con la 
finalidad de desarrollarse en lo personal y profesional por su bienestar y por el de su familia, así como poder integrarse plenamente al desarrollo social, cultural, económico y político en el que vive; manifestando que este proceso no tiene como finalidad el modificar o extinguir los derechos y obligaciones que hubiese contraído con anterioridad.

Para acreditar su acción y cumpliendo con los requisitos establecidos en el artículo 135 bis y 498 bis adicionado al Código Civil ofreció como pruebas de su parte las siguientes documentales públicas y privadas: copia certificada del acta de nacimiento; documental privada consistente en el dictamen pericial emitido por el doctor, en su calidad de médico, sicoterapeuta y sexólogo clínico, de fecha, del cual se desprende la siguiente conclusión:

"N", que era el nombre que le fue asignado de acuerdo a su identidad de género y a su rol o papel de género y por su deseo escogió el de "Na" el cual era contrario en cuanto al sexo de su nacimiento, ya que presentaba una discordancia entre su sexo biológico masculino y su identidad de género femenina, por ello, requería de ayuda profesional que le brindara la posibilidad de obtener la concordancia entre ambos.

A la fecha, Na, nombre que le fue otorgado después de acreditar todas las pruebas para ello, ha cumplido exitosamente con todas las pruebas de vida real en el papel de género deseado y recibido el tratamiento hormonal y psicoterapéutico, además de haberse sometido a la intervención quirúrgica como parte del proceso de reasignación para la concordancia sexogenérica.

Todo lo anterior, confirma su condición de mujer transexual, por lo que certifico, como su médico tratante, que ella está lista para asumir plenamente el papel de género concordante con su identidad de género femenina al modificar su nombre y sexo en sus documentos de identidad jurídica, lo que la llevará a poder contar con la acreditación legal que le permita vivir con el rol con el que socialmente se identifica y para el que se ha entrenado y preparado todos estos años.

Documental privada, consistente en la confirmación de dictamen, emitida por el médico, psicoterapeuta con experiencia clínica en procesos de reasignación para la concordancia sexogenérica, de fecha, de la cual se advierte lo siguiente:

Que confirmo el diagnóstico emitido por el Dr..., en su calidad de médico, psicoterapeuta, y sexólogo clínico, en relación al consultante N, quien pre- 
sentaba una discordancia entre su sexo biológico masculino y su identidad de género femenina, por ello, ratifico que la consultante ha efectuado exitosamente el proceso de reasignación para la concordancia sexo-genérica, dando como resultado su condición de mujer transexual.

Que de mi anamnesis, observancia clínica y exploración física de la persona tratada, confirmo que el proceso al que Na se sometió, resultó efectivo, adecuado y exitoso para su persona, pues ella refiere sentirse plena, segura y optimista sobre su futuro como mujer transexual.

La sensación de plenitud de $\mathrm{Na}$ es total, y refiere estar conciente sobre su imposibilidad para embarazarse, lo que no le impediría sin embargo, realizar una adopción en un momento dado, auque no sea prioridad en estos momentos.

Na refiere haber vencido todos los miedos que tuvo antes de lograr su reasignación sexogenérica y sentirse como una persona plena, adaptada, y realizada con su persona en su entorno social y productivo para ella, para su pareja y para su país.

En virtud de lo anterior, confirmo que el consultante N, quien desea ser reconocido con el nombre de $\mathrm{Na}$, ha tenido un seguimiento adecuado a su situación de mujer transexual, y que por ello está preparada para realizar el cambio de sexo y nombre que desea ante los tribunales a fin de obtener concordancia entre su identidad jurídica y el rol social de mujer con el que actualmente vive a fin de tener una vida plena, sana y productiva por su bienestar y el de su entorno social.

Con todas estas pruebas, acreditó haberse sometido al proceso de reasignación para la concordancia sexogenérica, cumpliendo con todas las pruebas de vida real en el papel de género deseado y recibido el tratamiento hormonal y sicoterapéutico correspondientes, además de haberse sometido a la intervención quirúrgica como parte del proceso de reasignación para la concordancia sexogenérica dando como resultado su condición de mujer transexual, ordenando al director del Registro Civil del Distrito Federal, realizar a favor de la persona que aparece registrada con el nombre de N, la anotación correspondiente en el acta de nacimiento primigenia y del mismo modo el levantamiento de una nueva acta de nacimiento por reasignacion de concordancia sexogenérica, en cuyo renglón correspondiente al nombre de la registrada se asentará el de $\mathrm{Na}$, y en el renglón correspondiente al género, se asentará el de femenino; para lo cual el acta de nacimiento del registrado quedará reservada y por ningún motivo se publicará ni expedirá constancia alguna, salvo mandamiento 
judicial, lo anterior en términos de lo dispuesto por el párrafo primero del artículo 498-bis del Código Civil adicionado, sin que ello implique actuar de mala fe, establecer o modificar la filiación, ni causar perjuicio a terceros. 